Article

\title{
Improving SBR Performance Alongside with Cost Reduction through Optimizing Biological Processes and Dissolved Oxygen Concentration Trajectory
}

\author{
Robert Piotrowski *, Aleksander Paul and Mateusz Lewandowski \\ Faculty of Electrical and Control Engineering, Gdańsk University of Technology, Narutowicza 11/12, \\ 80-233 Gdańsk, Poland; olek.luap@gmail.com (A.P.); lewand.mateusz@gmail.com (M.L.) \\ * Correspondence: robert.piotrowski@pg.edu.pl
}

Received: 7 May 2019; Accepted: 29 May 2019; Published: 31 May 2019

check for updates

Featured Application: This work is planned for implementation studies in wastewater treatment plants in the future. The proposed optimization algorithms can be used to solve optimization tasks with more decision variables.

\begin{abstract}
Authors of this paper take under investigation the optimization of biological processes during the wastewater treatment in sequencing batch reactor (SBR) plant. A designed optimizing supervisory controller generates the dissolved oxygen (DO) trajectory for the lower level parts of the hierarchical control system. Proper adjustment of this element has an essential impact on the efficiency of the wastewater treatment process as well as on the costs generated by the plant, especially by the aeration system. The main goal of the presented solution is to reduce the plant energy consumption and to maintain the quality of effluent in compliance with the water-law permit. Since the optimization is nonlinear and includes variations of different types of variables, to solve the given problem the authors performed simulation tests and decided to implement a hybrid of two different optimization algorithms: artificial bee colony (ABC) and direct search algorithm (DSA). Simulation tests for the wastewater treatment plant case study are presented.
\end{abstract}

Keywords: artificial bee colony algorithm; biological processes; direct search algorithm; hierarchical control; nonlinear optimization; sequencing batch reactor

\section{Introduction}

Wastewater treatment plant (WWTP) is a complicated system in which processes of removing contaminants from municipal and/or industrial wastewater take place. Physical, biological and chemical processes are used to remove contaminants before their discharge to the receiver. The activated sludge treatment approach, which uses bacteria and other microorganisms to remove contaminants by assimilating them, has been widely adopted in most WWTPs.

Batch type WWTP, sequencing batch reactor (SBR), is a popular method of municipal wastewater treatment. SBRs are a special form of activated sludge treatment in which all processes take place in the reactor tank. SBR is used for small-scale wastewater treatment and also becomes useful as a decentralized wastewater treatment technology for on-site treatment and/or water reuse technologies related to the sustainable water system. A typical sequence for an SBR system is: filling, biological reactions (aerobic, anaerobic), sedimentation, decantation and idle state [1].

From the control point of view, a WWTP is a very complex, dynamic, nonlinear, multivariable, hybrid control system where interactions between the components are strong. In addition, only limited measurements are available during plant operation. Unfortunately, simple linear control systems are very often used there, which cannot provide good control results at different points of operation. 
The right amount of dissolved oxygen (DO) is one of the key parameters influencing the effectiveness of biological processes taking place in the WWTP. This allows the microorganisms in the activated sludge to develop and to successively reduce nitrogen and phosphorus compounds in wastewater. Air is delivered into the aerobic zones by the aeration system (blowers, pipes and diffusers). Air allows oxygen to be transferred from the air to the liquid phase wastewater. The appropriate DO value in the SBR has a great effect on the treatment efficiency, operational costs and system stability. Moreover, the electricity consumption associated with the operation of the aeration system amounts to more than $50 \%$ of the operating costs at a WWTP [2]. Therefore, effective DO control is the key to savings. The dynamics of DO is nonlinear. Unfortunately, in industrial practice DO is usually controlled by a simple feedback loop (e.g., rule-based control, linear PI algorithm with constant parameters). Therefore, good control performance for all operating conditions cannot be achieved.

In other words, the effective operation of WWTPs requires the use of modern control and optimization techniques. Their implementation is justified in view of increasingly stringent standards. The costs of implementing effective control and optimization algorithms in a WWTP are much lower than its modernization.

Previous studies reported various structures and technologies of the DO control system. The cascade nonlinear adaptive control system, extended by the anti-windup filter, was applied [3]. Furthermore, the parameter analysis of the adaptive controller used for quality control was performed. Optimization of aeration profiles in the WWTP was shown [4]. First, the total rate of aeration was manipulated while employing equal rates of local aeration across. Then, scenarios with a nonuniform distribution of local aeration rates were investigated. The advanced control system of DO was designed [5]. Fuzzy PID control and a conventional PID control system were composed in a cascade structure. The control results showed that the control strategy reduced aeration energy consumption and guaranteed the stability of the system. In 2009, multivariable PID control system for biological WWTP with nitrification and denitrification was proposed [6]. The results showed that the performance of WWTP improved and it could potentially lead to energy saving and improvement in the removal of nitrogen. The multiregional PI controller for dissolved oxygen and aeration system control at biological WWTP was applied [7]. The control mechanism within the operating point area was based on PI controllers with the Takagi-Sugeno-Kang method of defuzzification. The proposed control strategy was designed based on the real data records and was validated by simulation. Other control algorithms using predictive control to control the DO concentration were used [8-10]. In 2018, the optimal variable setpoint and a setpoint tracking control system for the DO concentration were designed [11]. A constrained nonlinear neural network predictive controller was applied. Simulations results showed an improvement in effluent quality and reduction in energy use. A DO control system using neural network-based adaptive PID algorithm was proposed [12]. The powerful learning and adaptive ability of the radial basic function neural network were applied for adaptive adjustment of the PID parameters. Simulation results were showed that the novel control algorithm effectively improved the control accuracy of DO concentration as opposed to the classical PID controller. In 2017, the online hybrid intelligent control system based on a genetic algorithm to control of DO was applied [13]. The proposed hybrid approach proved to be a robust and effective DO control tool, attaining adequate effluent quality and minimizing the demand for energy.

DO control strategies using $\mathrm{NH}_{4}$ and $\mathrm{NO}_{3}$ measurements are designed. For example, two-level hierarchical control structure for $\mathrm{DO}$ and $\mathrm{NH}_{4}$ control was applied [14]. A predictive controller with inlet flow rate feedforward control was proposed for the lower level. Affine function and fuzzy controller were designed for the higher level. The control goal was to improve effluent quality and to reduce operational costs.

Other research works are based on the optimization of biological processes taking place in the SBR reactor. For this purpose, in addition to measuring DO, additional measurements are applied: $\mathrm{pH}$, Oxidation Reduction Potential—ORP [15], Oxygen Uptake Rate-OUR [16], aeration time, phase sequence (anaerobic/aerobic), phase duration, number of phases [17-19]. 
The approach presented in this paper, unlike any other, combines several advanced control technologies, for example: a hierarchical structure, supervisory controller with the optimizer and a controller with reference model to fully bridle complex dynamics of the control system. Two-step optimization with deterministic and non-deterministic algorithms allows to search for a solution of the optimization problem in a much more efficient way. Finally, the whole system is designed to calculate the operating settings and update them with each refill of the SBR, which makes it very precise and able to respond to any changes in the composition of sewage, noise or disturbances.

The paper presents a further development of the research works [20]. An optimization method of a difficult, nonlinear, nonconvex and hybrid (different decision-making variables) task has been proposed. The above features of the optimization task result from the properties of the control system (SBR with the aeration system). The paper considers the problem of optimizing the length and number of phases in SBR and determining the optimal DO reference trajectory. The aim was to minimize the electricity consumption associated with the pumping of air by the aeration system. At the same time, the limitations of the water-law permit for a sewage treatment plant operating in Northern Poland have been taken into account.

\section{Control Plant-Wastewater Treatment Plant and Aeration System}

The Swarzewo WWTP consists of three parts of wastewater treatment: mechanical, biological and chemical. This paper concerns the second part and one SBR with the capacity of $6400 \mathrm{~m}^{3} /$ day. Wastewater treatment is based on the activated sludge method. Figure 1 presents a single SBR cycle. It consists of the following phases: filling, biological reactions (aerobic, anaerobic), sedimentation, decantation and idle state. The excess sludge is removed and used as garden soil in the form of compost. The Baltic Sea is the effluent receiver [21].

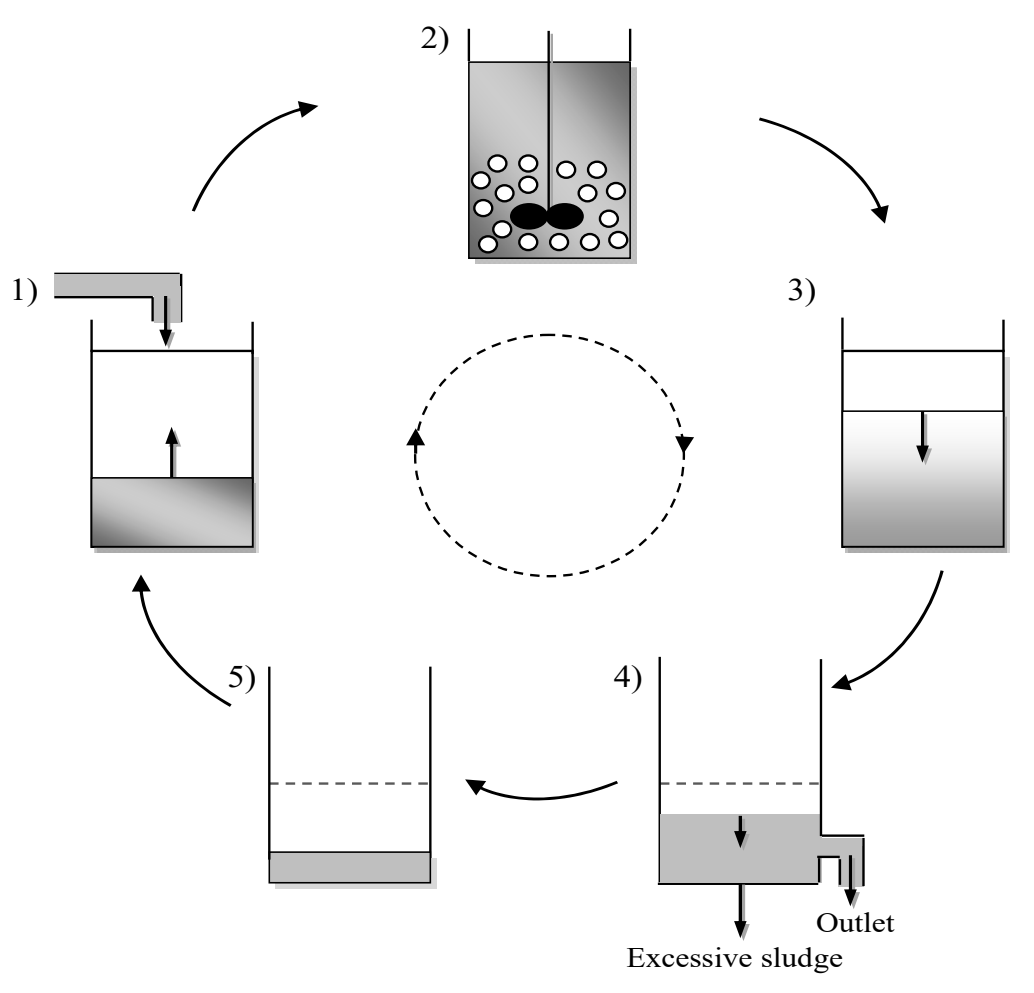

Figure 1. Phases of the SBR operating cycle: 1) filling 2) biological reactions (aerobic, anaerobic) 3) sedimentation 4) decantation 5) idle state.

Maximum acceptable pollutant concentrations of effluent, according to the water-law permit for Swarzewo WWTP, are: chemical oxygen demand $(\mathrm{COD})=125 \mathrm{~g} \mathrm{O}_{2} / \mathrm{m}^{3}$, total nitrogen $\left(N_{\text {tot }}\right)=15 \mathrm{~g}$ $\mathrm{N} / \mathrm{m}^{3}$, total phosphorus $\left(P_{t o t}\right)=2 \mathrm{~g} \mathrm{P} / \mathrm{m}^{3}$. 
The biological processes were modelled by applying ASM2d [22]. It is a popular mathematical description of biological processes at WWTPs. The overall model was calibrated according to the plant data records. The model was implemented in a simulation package, SIMBA [23], in order to obtain information data from the controlled plant. The verification of the modelling results was satisfactory they were used for control design [22].

As mentioned above, air is necessary for the monitoring of biological processes. It is supplied to the SBR by means of an aeration system. It consists of blowers, pipes and diffusers (see Figure 2). The aeration system supplies the SBR with oxygen by means of compressed air. From the control point of view, it is a complex, non-linear, dynamic and hybrid system.

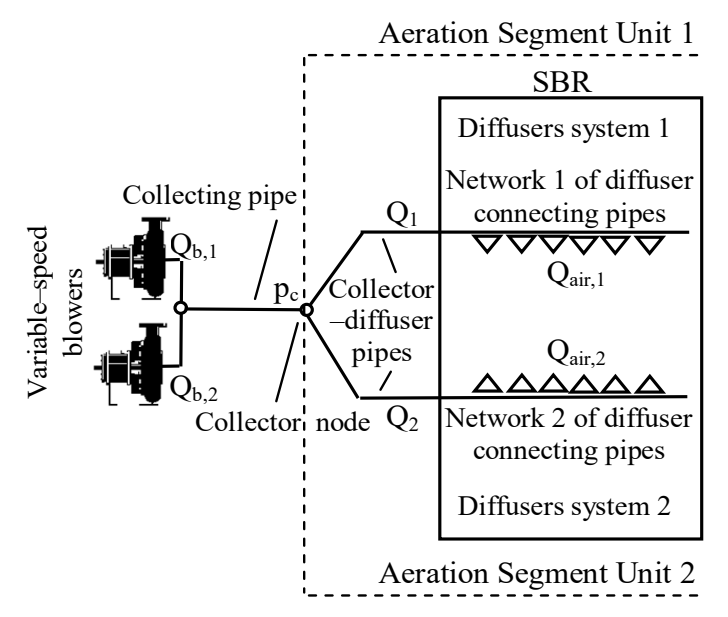

Figure 2. Structure of the Swarzewo aeration system.

The paper [24] presents the general methodology of process modelling of the aeration system. This model was applied and adapted to the case study aeration system. It was described by several linear and nonlinear algebraic and differential equations [22]. The model of the aeration system was implemented in the Matlab environment and was verified based on real data records from Swarzewo WWTP. Since the verification of modelling results proved satisfactory, they were used for control design.

\section{Hierarchical Control System}

The choice of a proper control system structure depends on several factors. In the investigated case the system has two different tasks which have to be managed simultaneously. On one side there is the control of the DO concentration, in sewage which is problematic due to complex internal dynamics with different time scales as well as nonlinearities and changing working conditions. The second task to consider consists of the management of the SBR work cycle, which includes selection of quantity and length of each of the phases during one work cycle.

\subsection{Structure and Its Main Parts}

It was decided to implement a hierarchical control structure which allows to control variable parameters with mixed dynamics as well as the proper management of the SBR work cycle. The general structure of the proposed control system is shown in Figure 3. 


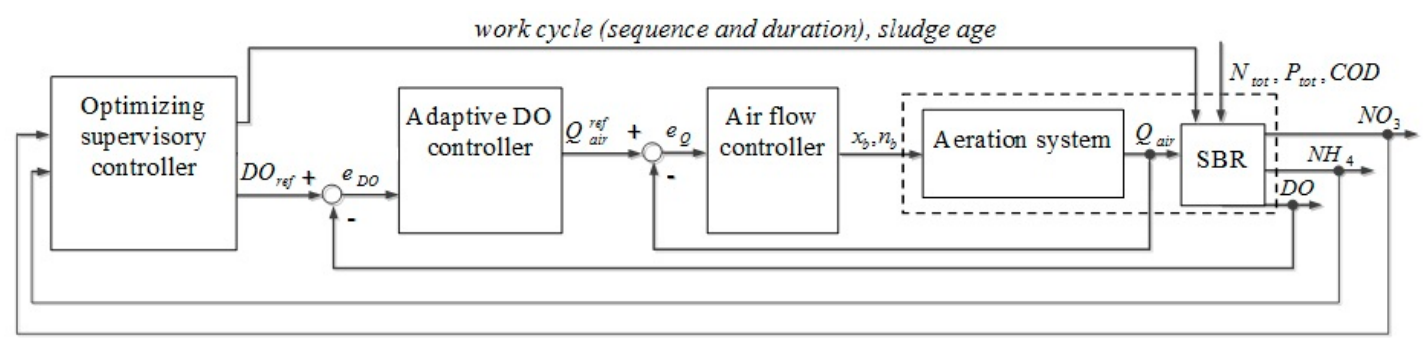

Figure 3. Structure of the hierarchical control system: $Q_{a i r}, n_{b}, x_{b}, e_{D O}, e_{Q}, N_{t o t}, P_{t o t}, \mathrm{COD}, \mathrm{NO}_{3}, \mathrm{NH}_{4}$ are the air flow $\left[\mathrm{m}^{3} / \mathrm{h}\right]$, blower speed [rpm], state of blower: on/off [-], error of DO $\left[\mathrm{g} \mathrm{O}_{2} / \mathrm{m}^{3}\right]$, error of air flow $\left[\mathrm{m}^{3} / \mathrm{h}\right]$, total nitrogen $\left[\mathrm{g} \mathrm{N} / \mathrm{m}^{3}\right]$, total phosphorus $\left[\mathrm{g} \mathrm{P} / \mathrm{m}^{3}\right]$, chemical oxygen demand $\left[\mathrm{g} \mathrm{O}_{2} / \mathrm{m}^{3}\right]$, nitrate concentration $\left[\mathrm{g} \mathrm{N} / \mathrm{m}^{3}\right]$, ammonia concentration $\left[\mathrm{g} \mathrm{N} / \mathrm{m}^{3}\right]$, respectively. The abbreviation for reference trajectory is designated as ref.

The air flow controller (lower level of the presented control system) is responsible for controlling fast-changing variables (seconds), while the adaptive DO controller manages the slowly changing ones.

Airflow is controlled through the internal model control (IMC) [25], which uses the inverted model of the aeration system to calculate the control signal for blowers. In order to create such signals, three different variables have to be monitored: reference and real airflow, as well as, the volume of wastewater in SBR. In general, two blowers are considered as independent equipment, which means that one is used as the main blower, and the other as an auxiliary. This action helps to control the usage of both blowers and extends the functionality of the presented air flow system [21].

Slower changing variables are managed through the controller with a reference model (direct model references adaptive control-DMRAC) [26]. In general, this solution allows the control system to adapt to the changing work conditions-complicated dynamics: nonlinearity and non-stationary plant and disturbance (respiration) by modifying the control law parameters. The implemented controller was modified because of the high level of complexity of the investigated plant to minimise the impact of constantly changing work conditions. Major changes affect the values of learning rates, anti-windup filter parameters and DMRAC starting points, which can be now adjusted during the optimization process to meet various conditions. In addition, the anti-windup filter reduces the impact of the control signal constraints, such as maximum rotational speed of blowers [27-29]. This part of the control system uses the control error $e_{D O}$ and $Q_{a i r}$ to calculate the $Q_{a i r}{ }^{\text {ref }}$ for the lower-level controller mentioned above.

Finally, the supervisory controller generates the DO reference trajectory to meet the trajectory as much as it is possible in various internal conditions during the work cycle. Details of this part of the control system are described in further sections of this paper.

\subsection{General Work Cycle of the Implemented System}

The general work cycle of the presented system consists of several steps (see Figure 1) which lead to complete treatment of effluent. A block diagram of the described work cycle is shown in Figure 4. The most important factor in the proposed solution is the step-feed strategy. This approach assumes the step-feed of sewage and the periodic aeration of the content of the SBR which allows to efficiently remove the nitrogen compounds without using any external source of carbon. The quantity of the refills during each cycle is determined through the asymmetric filling strategy alongside the changing number of biological (aerobic, anaerobic) phases during each refill. Each cycle is divided into a series of sequences depending on the intensity of wastewater inflow and the level of contamination. The capacity limit determines the specific volume of the last filling, regardless of the intensity of sewage inflow [29]. 

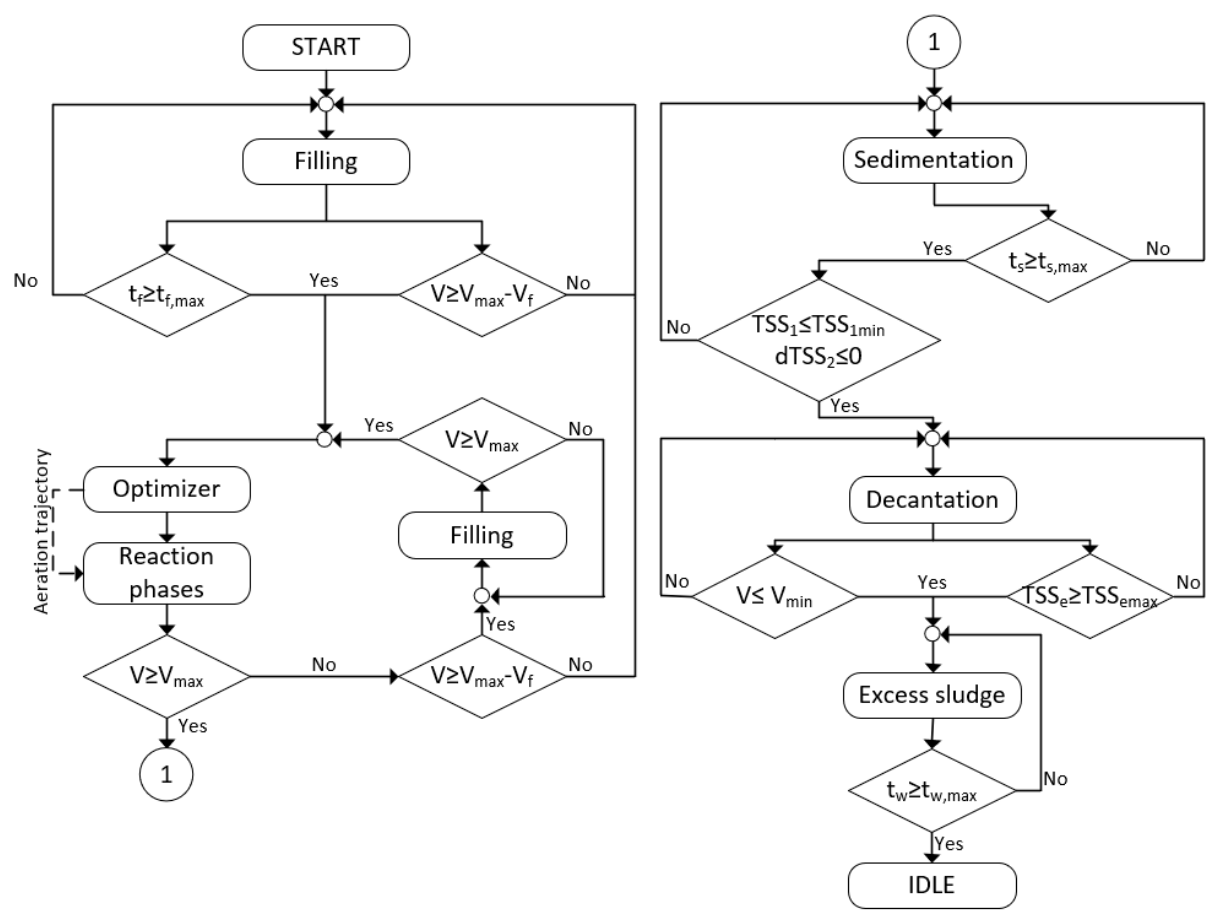

Figure 4. Block diagram of the work cycle: $t_{f}$ is the duration of the current filling [min]; $t_{f, \max }$ is a time limit on filling [min]; $t_{s}$ is the duration of sedimentation [min]; $t_{s, \max }$ is a time limit on sedimentation [min]; $t_{w}$ is the duration of excess sludge wasting [min]; $t_{w, \max }$ is a time limit on excess sludge wasting [min]; $V$ is the current volume of the wastewater-sludge mixture in the $\operatorname{tank}\left[\mathrm{m}^{3}\right] ; V_{\text {max }}$ is the maximum capacity of the tank $\left[\mathrm{m}^{3}\right] ; V_{\min }$ is the minimum volume of the mixture in the tank $\left[\mathrm{m}^{3}\right] ; V_{f}$ is the volume of the last filling $\left[\mathrm{m}^{3}\right] ; T_{1} S_{1}$ is the concentration of the TSS in the top layer of the tank and TSS 1 min is its limit $\left[\mathrm{g} / \mathrm{m}^{3}\right]$; TSS $_{e}$ is the concentration of the TSS in the effluent and TSS $_{\text {emax }}$ is its limit $\left[\mathrm{g} / \mathrm{m}^{3}\right]$; $d \mathrm{TSS}_{2}$ - derivative of the TSS concentration in the middle layer of the reactor $\left[\mathrm{g} / \mathrm{m}^{3}\right]$.

Biological reactions phase is the key factor in the whole wastewater treatment process. It has the most significant impact on the quality of treated sewage as well as energy consumption over the cycle. The number and duration of sequences (aerobic plus anaerobic), as well as the order of single reactions (aerobic, anaerobic), are discussed in further sections of this paper.

The management of the sedimentation is dependent on the total suspended solids (TSS), which is monitored in the top and mid layer of the SBR as well as minimal sedimentation time. Setting the correct time of this stage is very important in terms of efficient wastewater treatment process. Too long sedimentation phase may lead to the return of discharge of phosphates and as a result leave the sewage partly untreated. The decantation stage can start after reaching the minimal sedimentation time and when two conditions are fulfilled: TSS in the top layer is below assumed value and it decreases in the middle layer. This stage ends each time the volume of wastewater and active sludge reaches its minimal level or a specific amount of solids is detected in the wastewater.

\subsection{Optimization Process}

The complexity of the presented plant and the number of various choices which have to be taken 'online' during the work cycle impose implementing more advanced control solutions in such systems. This is why the authors of this paper decided to implement a supervisory controller responsible for adjusting the control system settings during its work to increase the efficiency and to minimize the maintenance costs. Most of them (almost $60 \%$ ) are generated by the aeration system which is the main part of the whole system taken under consideration in the optimization process in this paper. Designing such a controller, all the restrictions concerning the plant and water-law permit for Swarzewo WWTP have to be considered. To solve the optimization problem described in the further part of this paper, 
the authors decided to use the general approach, which combines deterministic and non-deterministic algorithms. As a result, the mentioned controller delivers proper information regarding the work cycle (quantity and length of aerobic/anaerobic phases) to the lower level parts of the control system for each refill of the SBR. Details of operating principles are described in further sections.

\subsubsection{Optimization Details}

A two-step optimization application (Figure 5 explains operating principles) is proposed which determines the aeration trajectory for each refill of the SBR tank and adjusts the settings of the control system to meet the established goal, minimization of operational cost of the WWTP, with SBR. It means that whenever the SBR is being refilled (see Figure 4), the designed optimizer runs and calculates the solution of the problem. Figure 4 shows only the overall operational principles without a detailed explanation of how the optimizer calculates the specific values.

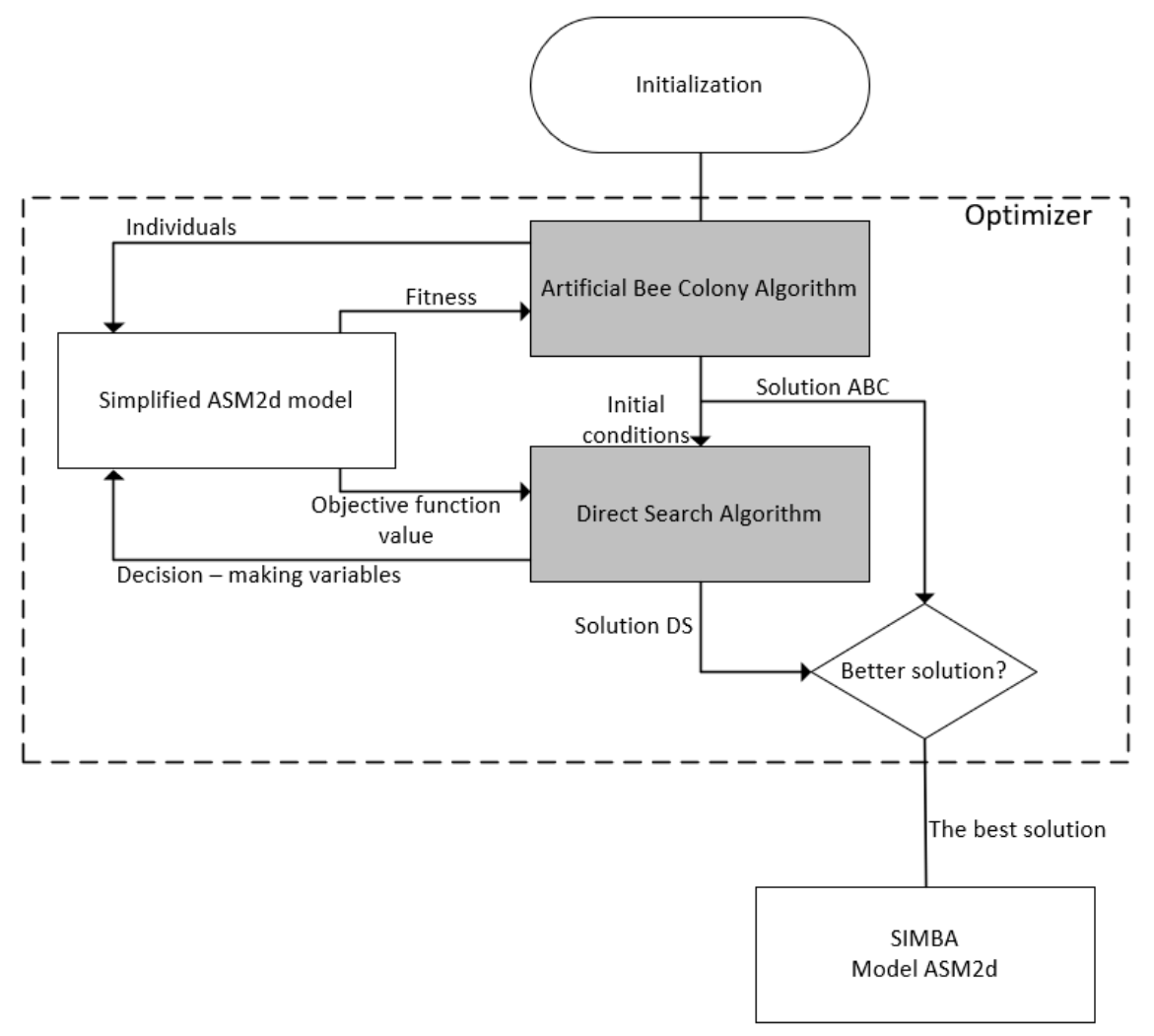

Figure 5. Scheme of the optimization process.

The principle of the optimizer's operation is based on two algorithms. In the first place, a non-deterministic algorithm ("Artificial Bee Colony Algorithm" block) is initiated after the filling phase. Inputs for this block are decision-making variables with random values in the range of given constraints. This block determines the best values of decision-making variables according to constraints in such a way that the value of the target function is as low as possible. Then calculated values of individual variables are sent to the deterministic algorithm ("Direct Search Algorithm" block), as starting conditions. Both algorithms use a simplified model of the SBR ("Simplified ASM2d model" block), which makes the calculation time shorter, but decreases the precision of the found solution. Next, the results of both of the algorithms are compared ("Better solution?" block), as a solution with the lower value of the objective function is sent to the control system with a more accurate SBR model ("SIMBA Model ASM2d" block) to simulate the work of the plant.

Figure 6 shows the course of exemplary trajectory of $D O_{\text {ref }}$ set by the optimizer described in this section. With each refill of the SBR tank, the designed supervisory controller with optimizer calculates 
the optimal solution of the objective function. The $D O_{\text {ref }}$ trajectory is being adapted to the existing biological conditions, thus it may look different after each refill.

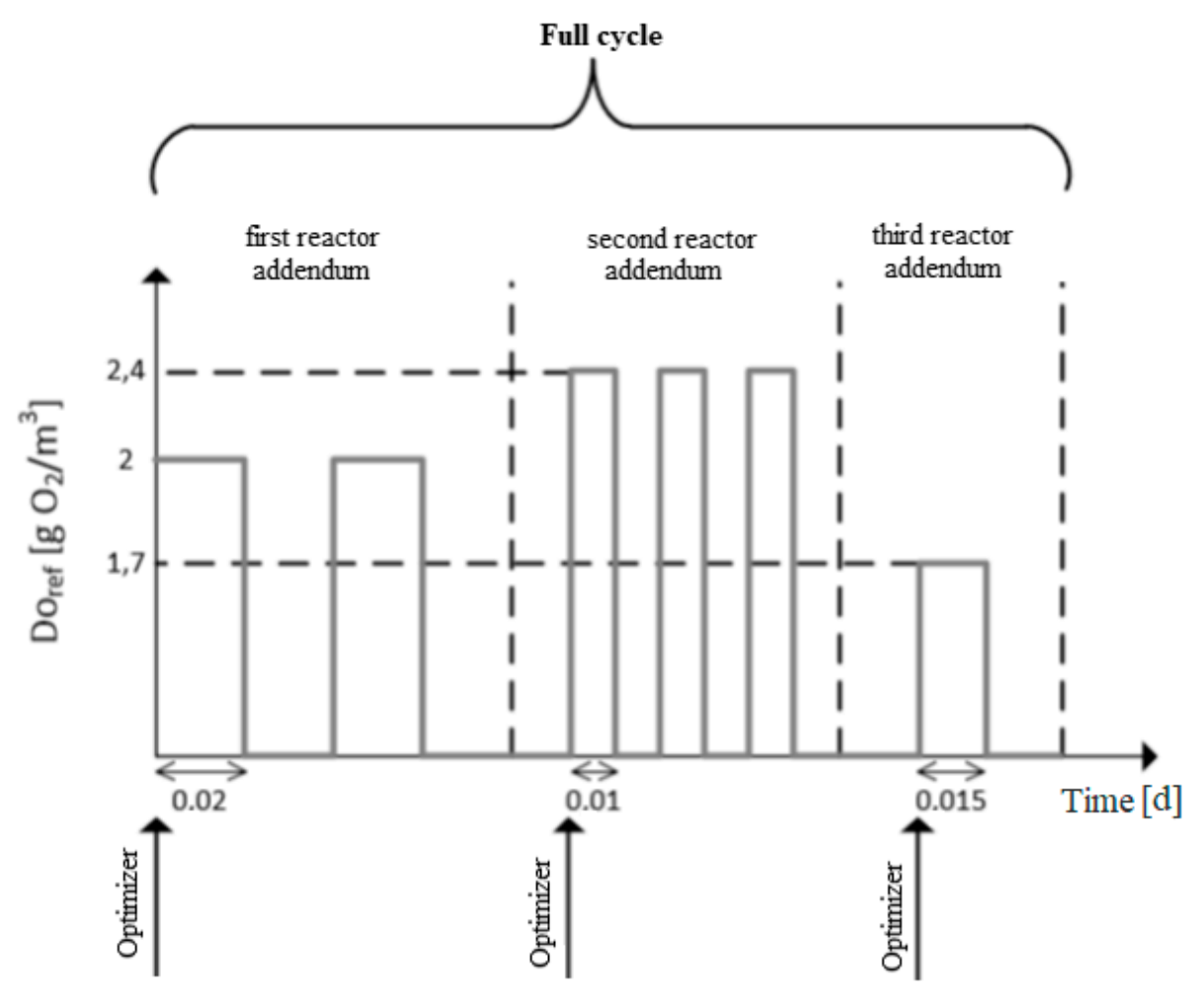

Figure 6. Example of $D O_{\text {ref }}$ trajectory.

Decision-Making Variables

Proper control of an SBR plant is a difficult and demanding task from both economical and performance point of view. The most significant step in the decision-making process is to formulate the optimization problem. Due to the significant complexity of the SBR wastewater treatment plant model together with the aeration system model, it was decided to use the partial nitrification approach. It guarantees relatively easy implementation and the possibility of effective de-pollution. However, this approach necessitates the use of different types of decision-making variables. Finding proper decision-making variables is a very complicated process and demands extensive knowledge about the technology of SBR plants and biological processes inside the plant. The efficiency of wastewater treatment in the active sludge technology is dependent on several key factors: aeration profile, temperature, sludge age and the quality of wastewater and its concentration. Aeration is the factor that has the biggest impact on the economic aspects of wastewater treatment, due to generating the highest cost. The number of decision-making variables has a direct impact on the complexity of the whole optimization process.

The following decision-making variables occur in the optimization task: $x_{1}$-the order of phases (aerobic -1 , or anaerobic - 0 , binary) [-], $x_{2}$ - phase length in day (floating point) [d], $x_{3}$-amount of the sequences (integer) [-] and $x_{4}$-value of $D O_{\text {ref }}$ (floating point) $\left[\mathrm{g} \mathrm{O}_{2} / \mathrm{m}^{3}\right]$.

It has to be noted that variables $x_{2}$ and $x_{3}$ relate to the pair of anaerobic and aerobic phases. It means that if the given optimizing application computes the solution which consists of two anaerobic phases 0.2-day length each, the amount and length of the aerobic phases will be exactly the same. Considering the given information, the total length of the reaction phase will remain at 0.8 day. $x_{3}=1$ means that the process consists of a single biological phase (aerobic and anaerobic). Another important issue is that $x_{1}$ is an indirect variable, which means it is not considered in the objective 
function. However, it has a significant impact on the examined problem and has to be included in the decision-making process.

All the constraints for the decision-making variables were set and adjusted during the simulation tests. Phase order $x_{1}$ is a binary variable (see (1)). The ones which are connected with the variables $x_{2}$ and $x_{3}$ are the result of the real constraints of the aerating system in Swarzewo WWTP. The limitations for $\mathrm{DO}_{\text {ref }}\left(x_{4}\right)$ arise from the basic knowledge about biological processes inside the SBR tank.

$$
\begin{gathered}
x_{1} \in\{0,1\} \\
0.01 \leq x_{2} \leq 0.08 \\
1 \leq x_{3} \leq 7 \\
1 \leq x_{4} \leq 3
\end{gathered}
$$

Formulation of the Optimization Task

The second step, after finding decision-making variables, is to form a proper optimization task. As stated in the previous section, the partial nitrification approach has been used, leading to mixed integer nonlinear problem (MINLP), which cannot be effectively solved with the standard optimization methods. In Section 3.3.1, it is stated that the authors of this paper decided to implement the multi-step optimizing application in which the main problem, aeration trajectory, is computed by two algorithms working together to achieve the certain goal of energy consumed over the cycle as well as quality in the outlet of SBR.

Taking into account the information presented above, the main aspect that affects the quality of the optimization is the aeration profile. This factor is the main contributor to economic losses, and the appropriate aeration phases allow for effective treatment of wastewater. The formulation of the optimization problem (decision-making variables, optimization function, constraints) with this type of solution was proposed earlier [20]. It was decided to use this solution, and then improve and adapt it to the requirements presented in the paper.

The objective function is as follows:

$$
\min \mathbf{J}=\min \left\{\begin{array}{lr}
\left\lfloor x_{3}\right\rfloor \cdot x_{2}+2 \cdot \bmod \left(x_{3}, 1\right) \cdot x_{2}+0.001 \cdot x_{3} \cdot x_{4}+f p & \text { for } \bmod \left(x_{3}, 1\right)<0.5 \\
\left(\left\lfloor x_{3}\right\rfloor+1\right) \cdot x_{2}+0.001 \cdot x_{3} \cdot x_{4}+f p & \text { for } \bmod \left(x_{3}, 1\right) \geq 0.5
\end{array}\right.
$$

where $\left\lfloor x_{3}\right\rfloor$ —floored decision-making variable $x_{3}[-], f p$-penalty function [-].

The objective function is divided into two parts depending on the division result of $x_{3}\left(\bmod \left(x_{3}, 1\right)\right)$. The first part is responsible for the case where the fractional part of the calculated length of the sequences is $<0.5$. For example, if $x_{3}=2.2$ then the fractional part $=0.2$ which means that this small piece has to be taken under consideration in the objective function. This is why the $\bmod \left(x_{3}, 1\right)$ is multiplied by two and connected with the $x_{2}$. If the fractional part of the computed solution (length of sequences) is $\geq 0.5$ (for example if $x_{3}=2.6$ then the fractional part $=0.6$ ) then the additional pair of anaerobic and aerobic phases are added to the objective function (second part of (5)).

Despite the obvious constraints which are the result of the functional principles of the presented system and the biological processes, the requirements for the quality of wastewater effluent should be considered as well. These are included in the external penalty function:

$$
\begin{gathered}
\text { fpenalty }=\text { fpenalty } C O D+\text { fpenalty } N_{\text {tot }}+\text { fpenalty } P_{\text {tot }} \\
\text { fpenalty } C O D=\left\{\begin{array}{r}
0 \text { for } C O D<120 \\
0.01 \cdot(C O D-120)^{2}+0.01 \text { for } C O D \\
18 \text { for } C O D>160
\end{array}\right.
\end{gathered}
$$




$$
\begin{gathered}
\text { fpenalty } N_{\text {tot }}=\left\{\begin{array}{c}
18 \text { for } N_{t o t}<0 \\
0 \text { for } N_{t o t} \in 0,12> \\
0.08 \cdot\left(N_{t o t}-12\right)^{2}+0.01 \text { for } N_{t o t} \\
18 \text { for } N_{t o t}>20
\end{array} \in(12,20>\right. \\
18 \text { for } P_{t o t}<0 \\
\text { fpenalty } P_{t o t}=\left\{\begin{array}{c}
\text { for } P_{t o t} \in<0,1.5> \\
0.02 \cdot\left(P_{t o t}-1\right)^{2}+0.01 \text { for } P_{t o t} \in(1.5,5> \\
18 \text { for } P_{t o t}>5
\end{array}\right.
\end{gathered}
$$

The optimization task formulated above allowed to obtain promising results of the SBR reactor's work, which is presented in the further part of the paper.

\subsubsection{Optimization Methods}

The optimization task is nonlinear, nonconvex and hybrid (different forms of decision-making variables; two of them are real-type variables $\left(x_{3}, x_{4}\right)$, the third one is an integer $\left(x_{2}\right)$, the last $\left(x_{1}\right)$ is a binary variable. Initially, the previous optimization structure and algorithms were used [20]. During the research work, some other non-deterministic algorithms were found that could work better than the initially used method (evolutionary algorithm).

The artificial bee colony $(\mathrm{ABC})$ algorithm (see Figure 5) can achieve better results than the differential evolution algorithm [30,31]. ABC algorithm is based on a simulation of a swarm of honey bees searching for sources feeds. This is a non-deterministic method and it uses both randomness and heuristic methods to find a global minimum of any function.

The second optimization method is the direct search algorithm (DSA) (see Figure 5). This is a deterministic method which means that it does not have a stochastic factor in it. In order to find an optimal value, DSA needs information about a set of points around the starting one and then it calculates which one has the lowest value of the goal function [32].

\subsection{Control of Sludge Retention Time}

The amount of excess sludge that is wasted during the idle phase has a crucial impact on overall SBR efficiency, as it determines the sludge retention time (SRT), which is the average period of time in which the activated sludge solids have remained in the system. This quantity affects the type of microorganisms in the biomass, the sludge mass and sludge load, respiration rate or sludge settling. In order to maintain the desired SRT, the proper volume of excess sludge has to be pumped out of the SBR. This amount depends on, among others, total suspended solids in the tank and outflow of treated wastewater [29].

\subsection{Parameters of $D O$ Controller}

The use of a step-feed strategy has repercussions in the form of gradual changes in two important quantities-breathing rate and pressure in the aeration system-between successive phases of the biological reaction. The former is the disturbance of the DO control and the latter has a significant effect on the limitations and efficiency of the aeration system. The mechanism of gradual adaptation of DMRAC learning rate, AW filter yields and DMRAC initial parameters allow to improve the efficiency of the controller in the case of a step-by-step feeding strategy. The supervising controller counts the subsequent phases of the biological reaction and applies one of the predefined sets of parameters to DMRAC accordingly. The set is used during the entire biological reaction phase, regardless of the number of sequences [28].

\section{Optimization Results and Discussion}

The main goal of implementing the described control system with an optimizer is to improve the efficiency of WWTP and to minimize the incurred costs over one cycle at the same time. This leads to 
an overall enhancement of the whole system, including higher amount and quality of treated effluent alongside with the cost reduction.

The aeration system of the plant and the control system with an optimizer were designed and implemented in Matlab software with the additional SIMBA package, which allows to simulate the work of wastewater treatment plants. The reference control algorithm, with fixed time limits (like the one in Swarzewo WWTP), was prepared in order to compare the obtained results with the described system. Slight change-replacement of the existing PI controller (DO) for the cascade system - had to be done to provide the common basis for the comparison.

The optimization tests were conducted for two different scenarios with fixed inflow $\left(5000 \mathrm{~m}^{3} / \mathrm{d}\right)$ and various contamination levels of effluent, which are: $C O D=535 \mathrm{~g} \mathrm{O}_{2} / \mathrm{m}^{3}, N_{\text {tot }}=55 \mathrm{~g} \mathrm{~N} / \mathrm{m}^{3}$ and $P_{\text {tot }}$ $=7.38 \mathrm{~g} \mathrm{P} / \mathrm{m}^{3}$ for the 1 st one and $C O D=1070 \mathrm{~g} \mathrm{O}_{2} / \mathrm{m}^{3}, N_{t o t}=110 \mathrm{~g} \mathrm{~N} / \mathrm{m}^{3}$ and $P_{\text {tot }}=14.75 \mathrm{~g} \mathrm{P} / \mathrm{m}^{3}$ for the second one. The maximum acceptable pollutant concentrations of effluent, according to the water-law permit for Swarzewo WWTP, are listed in Section 2 of this paper. In the course of the conducted tests, three different types of control systems were compared: new control system with optimizer (symbol $\mathrm{OP})$, reference control system mentioned above (symbol CU) and the heuristic system with supervisory controller [29] (symbol HE).

The amount of energy consumed by a single SBR operating cycle is as follows:

$$
E(t)=\frac{s}{3600} \cdot \int_{0}^{t_{s}} p(\tau) \cdot Q_{a i r}(\tau) d \tau
$$

where: $E$-energy related to the work of blowers [kWh], s-inverse of the blowers efficiency coefficient, $t_{s}$-simulation time $[\mathrm{s}], p(t)$-fleeting value of pressure in the aeration system $[\mathrm{kPa}]$ and $Q_{\text {air }}(t)$-fleeting value of the air flow volume $\left[\mathrm{m}^{3} / \mathrm{d}\right]$.

Energy cost, defined as the amount of energy consumed to treat $1 \mathrm{~m}^{3}$ of wastewater, is the ratio of overall energy consumption and the amount of treated wastewater per cycle. The level of active volume during tests was set to $971 \mathrm{~m}^{3}$.

The results obtained for each of the control systems are compared one to another in the further part of this section. Formula (12) is used to calculate the level (percentage) of improvement:

$$
Z=\frac{x-y}{|x|} \cdot 100 \%
$$

where: $Z$ — the value of calculated comparison criteria [\%], $x$-base data/point and $y$-compared data/point.

Table 1 presents the values of important pollution indexes (COD, $\left.N_{t o t}, P_{t o t}\right)$ as well as the efficiency and energy cost indexes which are the main reasons to optimize the work of the SBR plant.

\begin{tabular}{|c|c|c|c|c|c|c|c|c|c|c|}
\hline Scenario & System & $\begin{array}{c}C O D_{i n} \\
{\left[\mathrm{~g} \mathrm{O}_{2} / \mathrm{m}^{3}\right]}\end{array}$ & $\begin{array}{c}C O D_{\text {out }} \\
{\left[\mathrm{g} \mathrm{O}_{2} / \mathrm{m}^{3}\right]}\end{array}$ & $\begin{array}{l}\text { Red. } \\
{[\%]}\end{array}$ & $\begin{array}{c}N_{t o t, i n} \\
{\left[\mathrm{~g} \mathrm{~N} / \mathrm{m}^{3}\right]}\end{array}$ & $\begin{array}{c}N_{t o t, o u t} \\
{\left[\mathrm{~g} \mathrm{~N} / \mathrm{m}^{3}\right]}\end{array}$ & $\begin{array}{l}\text { Red. } \\
{[\%]}\end{array}$ & $\begin{array}{c}P_{t o t, i n} \\
{\left[\mathrm{~g} \mathrm{P} / \mathrm{m}^{3}\right]}\end{array}$ & $\begin{array}{c}P_{\text {tot,out }}[\mathrm{g} \\
\left.\mathbf{P} / \mathbf{m}^{3}\right]\end{array}$ & $\begin{array}{l}\text { Red. } \\
{[\%]}\end{array}$ \\
\hline \multirow{3}{*}{ I } & $\mathrm{CU}$ & 535 & -79 & 100 & 55 & 8.0 & 85.5 & 7.38 & 6.6 & 10.6 \\
\hline & $\mathrm{HE}$ & 535 & -81 & 100 & 55 & 2.9 & 94.7 & 7.38 & 0.48 & 93.5 \\
\hline & OP & 535 & -58.1 & 100 & 55 & 12.12 & 77.9 & 7.38 & 0.78 & 89.4 \\
\hline \multirow[b]{2}{*}{ II } & $\mathrm{CU}$ & 1070 & -126 & 100 & 110 & 9.2 & 91.6 & 14.75 & 11.4 & 22.8 \\
\hline & HE & 1070 & -93 & 100 & 110 & 4.3 & 96.1 & 14.75 & 2.24 & 84.8 \\
\hline
\end{tabular}

Table 1. Comparison of pollutant concentrations for polluted and purified wastewater.

Taking into account the contamination rates of the SBR plant production, the best results have a structure with a heuristic control system, and the worst is the reference system from Swarzewo. As shown in Table 1, the original SBR plant control system works well with nitrogen purification but does not work at all in terms of phosphorus use. A control system with a heuristic controller 
achieving the best result in almost all cases failed to reduce phosphorus in the output wastewater for Scenario II, which shows that a system with an optimizer can be a little more consistent in terms of compliance with the limit values for pollution indicators. The objective function that has been used in the optimizer focuses mainly on reducing energy costs for wastewater treatment. For this reason, the output wastewater pollution indicators are not so important and are maintained only at the limits. A hierarchical control system with an optimizer works slightly worse in terms of numerical values than a system with a heuristic controller, but if one looks at binary results (1-maintained limit values, 0 -no), there is only one structure that performs all the tasks.

Another significant aspect in evaluating the operation of a control system with an optimizer is the amount of energy required to treat wastewater during the full cycle of the SBR plant. Table 2 shows three important indicators: efficiency $\left(E_{f}\right)$, energy $\operatorname{cost}\left(E_{c}\right)$ and energy to perform a single work cycle (E).

Table 2. Comparison of efficiency, energy cost and energy to perform a single work cycle.

\begin{tabular}{ccccc}
\hline Scenario & System & $\mathrm{E}_{\mathbf{f}}\left[\mathbf{m}^{3} / \mathbf{d}\right]$ & $\mathrm{E}_{\mathbf{c}}\left[\mathbf{k W h} / \mathbf{m}^{3}\right]$ & $\mathrm{E}[\mathbf{k W h} / \mathbf{c y c l e}]$ \\
\hline \multirow{4}{*}{$\mathrm{I}$} & $\mathrm{CU}$ & 1203 & 0.4192 & 751 \\
& $\mathrm{HE}$ & 2266 & 0.3269 & 317.5 \\
& $\mathrm{OP}$ & 1846.7 & 0.2184 & 212.1 \\
\hline \multirow{3}{*}{ II } & $\mathrm{CU}$ & 1203 & 0.6023 & 1080 \\
& HE & 2021 & 0.4427 & 430.4 \\
& OP & 1249.3 & 0.4152 & 403.2 \\
\hline
\end{tabular}

As can be seen in Table 2, the main objective of the optimizer application has been met. Energy cost is the lowest for both scenarios, as is the energy needed to perform one full cycle work. The worst results in each of the presented indicators are shown by the control system in Swarzewo. This is due to the fact that a simple timer-based control system has been used in the actual treatment plant. A positive aspect of this solution is the guarantee of always treating the same amount of wastewater at a constant known time. The heuristic controller has the best efficiency ratio and, compared to Swarzewo, significantly reduces the amount of energy required for wastewater treatment. This performance efficiency is guaranteed by assumptions of this structure, which included at least two full work cycles in one day. This assumption did not occur in the process of creating an optimizer for the SBR plant. Therefore, the performance in a structure with an optimizer is the most varied. Other factors, such as energy and energy costs in one work cycle, are minimized even more than with the heuristic method. The optimization of these two parameters was the main objective of the proposed optimizer and the implementation of this assumption looks very optimistic.

DO are illustrated in Figures 7 and 8. These apply to Scenario II, which usually occurs in Swarzewo WWTP.

Figure 7 shows three complete cycles of SBR installations. As it can be seen, the DO values and the number of aerobic phases for each additional portion of wastewater vary significantly. This is because the optimizer initially randomly searches for the best solution, so one can find many combinations of DO, number of sequences and phase lengths that can be optimal for each case. This diversity of optimal solutions is also the result of changes in the biological environment inside the reactor.

Figure 8 shows the magnification of the $\mathrm{DO}$ and it is, therefore, easier to compare $\mathrm{DO}$ with $D O_{r e f}$. The SBR is a very complex plant and does not allow real DO capacity to deal with the $D O_{\text {ref }}$ perfectly. Therefore, some overshootings and other imperfections of the DO are acceptable. However, the serious problem of the optimizer is that sometimes it can find solutions that are almost impossible to apply in the simulation and can cause problems in keeping contaminant parameters within their limits. This can be particularly the case if the input wastewater is heavily polluted. 


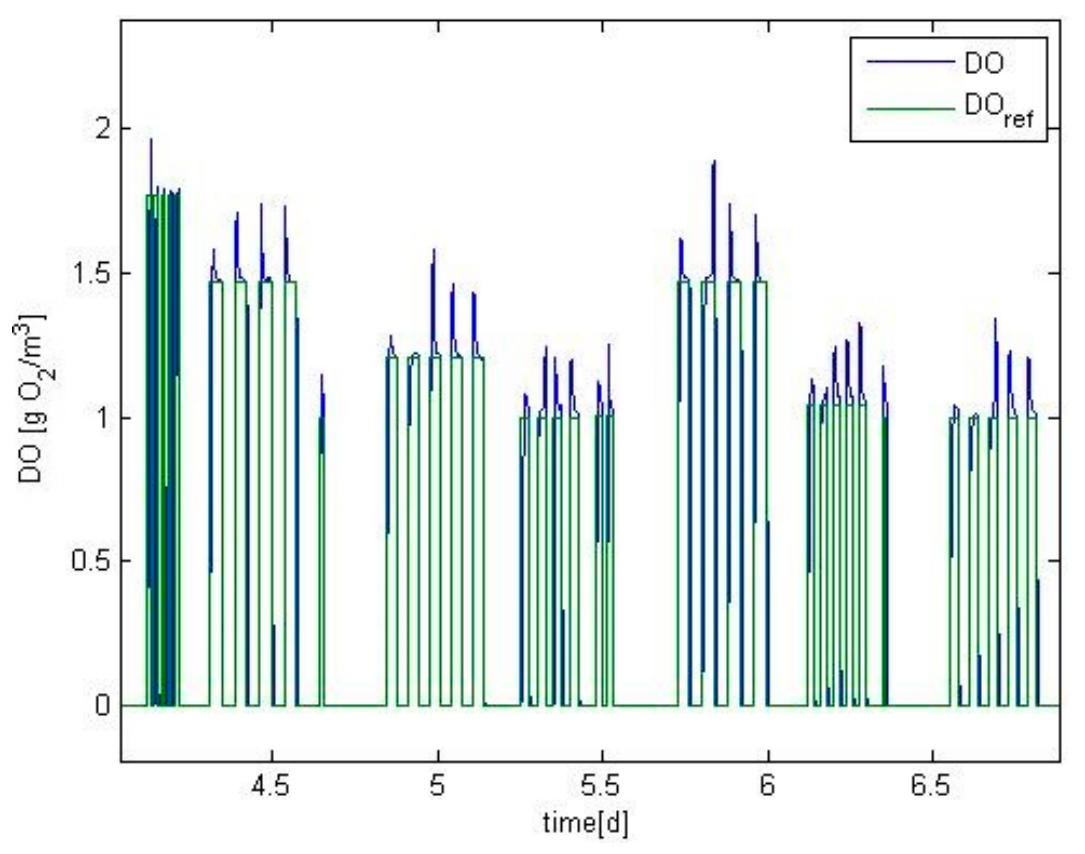

Figure 7. Dissolved oxygen.

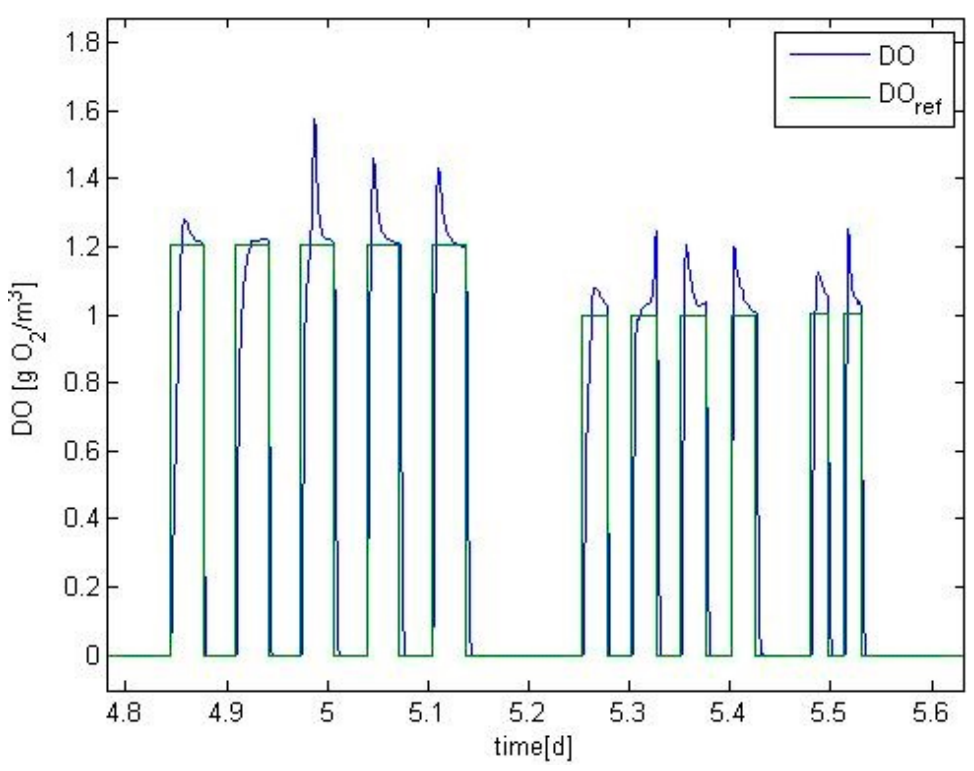

Figure 8. Dissolved oxygen-zoom.

\section{Conclusions}

In a time of growing awareness of the negative impact of pollution on the environment, SBR plants have become more and more popular in the business over the last years. The main advantage of this type of system is its flexibility, which allows to adjust the work parameters to the various conditions. On the other hand, such a plant is very complex and requires great knowledge of the biochemical aspects as well as the advanced control system to conduct the treatment process in the most efficient way. The lack of both advanced solutions and a basic control system in Swarzewo WWTP, as well as the growing need of environmental protection, were the main reasons why the authors decided to design and test the described control system with an optimizer.

The conducted simulation tests of the designed system show that it works in a much more efficient way than the reference one implemented in Swarzewo WWTP. The cost results are also better than the one obtained in paper [29]. One difference, in the outcomes obtained with the designed system and 
the compared ones, must be highlighted-various values of pollution indexes. This is the result of different aims of the compared systems. The one presented in this paper focuses on the minimization of the operational cost of the SBR plant with respect to environmental constraints. Therefore, the cost factor in the presented case is more important than obtaining very good environmental results.

To sum up, in the article:

1. Hierarchical control system with optimizing supervisory controller was proposed.

2. Methodology of resolving the complex, nonlinear and hybrid optimization problem was proposed.

3. Obtained test results were compared with the data featured in the previous paper [29] and with the WWTP in Swarzewo-in each case designed system with optimizer achieves better results from $6.3 \%$ up to $71.8 \%$ depending on the scenario and compared control system.

4. Major assumptions-reduction of plant energy consumption while maintaining the quality of effluent in compliance with the water-law permit-were achieved.

Author Contributions: Conceptualization, R.P.; methodology, R.P.; software, A.P. and M.L.; validation, R.P., A.P. and M.L.; investigation, R.P., A.P. and M.L.; writing—original draft, A.P. and M.L.; writing—review and editing, R.P.

Funding: This research received no external funding.

Conflicts of Interest: The authors declare no conflict of interest.

\section{References}

1. Wilderer, P.A.; Irvine, R.L.; Goronszy, M. Sequencing Batch Reactor Technology. Scientific and Technical Report No. 10; IWA Publishing: London, UK, 2001.

2. Jenkins, T.E. Aeration Control System Design. A Practical Guide to Energy and Process Optimization; John Wiley \& Sons: Hoboken, NJ, USA, 2013.

3. Piotrowski, R.; Błaszkiewicz, K.; Duzinkiewicz, K. Analysis the Parameters of the Adaptive Controller for Quality Control of Dissolved Oxygen Concentration. Inf. Technol. Control 2016, 45, 42-51. [CrossRef]

4. Ozturk, M.C.; Serrat, F.M.; Teymour, F. Optimization of Aeration Profiles in the Activated Sludge Process. Chem. Eng. Sci. 2016, 139, 11-14. [CrossRef]

5. Dai, H.Z.; Huang, M.J.; Li, C.; Zhang, Y.N. Research of the Dissolved Oxygen Intelligent Control System in the Aeration System of Wastewater Treatment. Appl. Mech. Mater. 2013, 433-435, 1136-1140. [CrossRef]

6. Wahab, N.A.; Katebi, R.; Balderud, J. Multivariable PID control design for activated sludge process with nitrification and denitrification. Biochem. Eng. J. 2009, 45, 239-248. [CrossRef]

7. Piotrowski, R.; Zawadzki, A. Multiregional PI control strategy for dissolved oxygen and aeration system control at biological wastewater treatment plant. In Proceedings of the 17th IEEE International Conference on Emerging Technologies \& Factory Automation (ETFA 2012), Cracow, Poland, 17-21 September 2012.

8. Mulas, M.; Tronci, S.; Corona, F.; Haimi, H.; Lindell, P.; Heinonen, M.; Vahala, R.; Baratti, R. Predictive control of an activated sludge process: An application to the Viikinmäki wastewater treatment plant. J. Process Control 2015, 35, 89-100. [CrossRef]

9. Piotrowski, R. Two-Level Multivariable Control System of Dissolved Oxygen Tracking and Aeration System for Activated Sludge Processes. Water Environ. Res. 2015, 87, 3-13. [CrossRef] [PubMed]

10. Grochowski, M.; Rutkowski, T.A. Supervised model predictive control of wastewater treatment plant. In Proceedings of the 21st International Conference on Methods and Models in Automation and Robotics (MMAR 2016), Międzyzdroje, Poland, 29 August-1 September 2016.

11. Sadeghassadi, M.; Macnab, C.J.B.; Gopaluni, B.; Westwick, D. Application of neural networks for optimal-setpoint design and MPC control in biological wastewater treatment. Comput. Chem. Eng. 2018, 115, 150-160. [CrossRef]

12. Du, X.; Wang, J.; Jegatheesan, V.; Shi, G. Dissolved Oxygen Control in Activated Sludge Process Using a Neural Network-Based Adaptive PID Algorithm. Appl. Sci. 2018, 8, 261. [CrossRef]

13. Ruan, J.; Zhang, C.; Li, Y.; Li, P.; Yang, Z.; Chen, X.; Huang, M.; Zhang, T. Improving the efficiency of dissolved oxygen control using an on-line control system based on a genetic algorithm evolving FWNN software sensor. J. Environ. Manag. 2017, 187, 550-559. [CrossRef] 
14. Santín, I.; Pedret, C.; Vilanova, R. Applying variable dissolved oxygen set point in a two level hierarchical control structure to a wastewater treatment process. J. Process Control 2015, 28, 40-55. [CrossRef]

15. Fan, L.; Xie, Y. Optimization Control of SBR Wastewater Treatment Process Based on Pattern Recognition. Procedia Environ. Sci. 2011, 10, 20-25. [CrossRef]

16. Traoré, A.; Corominas, L.; Puig, S.; Grieu, S.; Thiery, F.; Polit, M.; Colprim, J. Dissolved oxygen control and phases duration optimization in a sequencing batch reactor pilot plant. In Proceedings of the 17th IMACS World Congress on Scientific Computation, Applied Mathematics and Simulation, Paris, France, 11-15 July 2005.

17. San Martín, J.A.D.; Bournazou, M.N.; Neubauer, P.; Barz, T. Mixed integer optimal control of an intermittently aerated sequencing batch reactor for wastewater treatment. Comput. Chem. Eng. 2014, 71, 298-306. [CrossRef]

18. Wu, X.; Zhu, J.; Cheng, J.; Zhu, N. Optimization of three operating parameters for a two-step fed sequencing batch reactor (SBR) system to remove nutrients from swine wastewater. Appl. Biochem. Biotechnol. 2015, 175, 2857-2871. [CrossRef] [PubMed]

19. Flores-Tlacuahuac, A.; Pedraza-Segura, L. Optimal model-based aeration control policies in a sequencing batch reactor. Comput. Chem. Eng. 2016, 85, 124-135. [CrossRef]

20. Piotrowski, R.; Hirsch, P.; Lorenc, J. Comparison of Algorithms for Hybrid Nonlinear Optimization Problem in Biological Wastewater Treatment Plant. In Proceedings of the International Interdisciplinary PhD Workshop (I2PhDW 2018), Świnoujście, Poland, 9-12 May 2018.

21. Piotrowski, R.; Skiba, A. Nonlinear Fuzzy Control System for Dissolved Oxygen with Aeration System in Sequencing Batch Reactor. Inf. Technol. Control 2015, 44, 182-195. [CrossRef]

22. Henze, M.; Gujer, W.; Mino, T.; Matsuo, T.; Wentzel, M.C.; Marais, G.v.R.; van Loosdrecht, M.C.M. Activated Sludge Model No. 2d, ASM2d. Water Sci. Technol. 1999, 39, 65-182. [CrossRef]

23. Simba. User's Guide. Available online: http://simba.ifak.eu/simba/ (accessed on 1 May 2019).

24. Piotrowski, R.; Brdyś, M.A.; Konarczak, K.; Duzinkiewicz, K.; Chotkowski, W. Hierarchical dissolved oxygen control for activated sludge processes. Control Eng. Pract. 2008, 16, 114-131. [CrossRef]

25. Garcia, C.E.; Morari, M. Internal model control. A unifying review and some new results. Ind. Eng. Chem. Process Des. Dev. 1982, 21, 308-323. [CrossRef]

26. Åström, K.J.; Wittenmark, B. Adaptive Control, 2nd ed.; Addison-Wesley: New York, NY, USA; Prentice Hall: Upper Saddle River, NJ, USA, 2008.

27. Błaszkiewicz, K.; Piotrowski, R.; Duzinkiewicz, K. A Model-Based Improved Control of Dissolved Oxygen Concentration in Sequencing Wastewater Batch Reactor. Stud. Inform. Control 2014, 23, 323-332. [CrossRef]

28. Hirsch, P.; Piotrowski, R.; Duzinkiewicz, K. Two-Step Model Based Adaptive Controller for Dissolved Oxygen Control in Sequencing Wastewater Batch Reactor. In Proceedings of the 20th International Conference on Methods and Models in Automation and Robotics (MMAR 2015), Międzyzdroje, Poland, 24-27 August 2015.

29. Hirsch, P.; Piotrowski, R.; Duzinkiewicz, K.; Grochowski, M. Supervisory Control System for Adaptive Phase and Work Cycle Management of Sequencing Wastewater Treatment Plant. Stud. Inform. Control 2016, 25, 153-162. [CrossRef]

30. Karaboga, D.; Akay, B. A comparative study of Artificial Bee Colony algorithm. Appl. Math. Comput. 2009, 214, 108-132. [CrossRef]

31. Muthiah, A.; Rajkumar, R. A Comparison of Artificial Bee Colony algorithm and Genetic Algorithm to Minimize the Makespan for Job Shop Scheduling. Procedia Eng. 2014, 97, 1745-1754.

32. Kolda, T.G.; Lewis, R.M.; Torczon, V. Optimization by Direct Search: New Perspectives on Some Classical and Modern Methods. ASIAM Rev. 2003, 45, 385-482. [CrossRef]

(C) 2019 by the authors. Licensee MDPI, Basel, Switzerland. This article is an open access article distributed under the terms and conditions of the Creative Commons Attribution (CC BY) license (http://creativecommons.org/licenses/by/4.0/). 